\title{
PROTOTYPE DESIGN OF AN ENGINEER COLLISION PROTECTION SYSTEM
}

\author{
Michelle P. Muhlanger \\ Kristine Severson \\ Benjamin Perlman \\ U.S. Department of Transportation \\ Volpe National Transportation Systems Center \\ Cambridge, MA USA
}

\author{
Anand Prabhakaran \\ Som P. Singh \\ Anand R. Vithani \\ Sharma \& Associates, Inc. \\ Countryside, IL, USA
}

\section{ABSTRACT}

This research program was sponsored by the Federal Railroad Administration (FRA) Office of Research and Development in support of the advancement of improved safety standards for passenger rail vehicles. In a train collision, the cab or locomotive engineer is in a vulnerable position at the leading end of the vehicle. As cars with increased crashworthiness are introduced into service, there is a greater potential to preserve the space occupied by the engineer following an accident. In particular, full-scale impact tests have demonstrated the engineer's space can be preserved at closing speeds up to $30 \mathrm{mph}$. When sufficient survival space is preserved, the next objective is to protect the engineer from the forces and accelerations associated with secondary impacts between the engineer and the control cab. Given the hard surfaces and protruding knobs in a control cab, even a low speed collision can result in large, concentrated forces acting upon the engineer.

Researchers have designed a passive (i.e., requiring no action by the operator) interior protection system for cab car and locomotive engineers. The occupant protection system will protect engineers from the secondary impact that occurs following a frontal train impact, when the engineer impacts the control console. The protection system will result in compartmentalization of a 95th percentile anthropomorphic test device (ATD), and measured injury criteria for the ATD's head, chest, neck, and femur that are below those currently specified in Federal Motor Vehicle Safety Standard (FMVSS) 208 [1].

The system that has been developed to protect the engineer includes a specialized airbag and a knee bolster with energy absorbing honeycomb material and deformable brackets. Finite element and lumped mass-spring analyses show the effectiveness of the system in limiting the injury criteria to survivable limits. Component tests have measured the key characteristics of the airbag and the knee brackets and have provided test data necessary to validate the analyses.

Two tests were conducted to validate the airbag model. A static deployment test of the airbag measured the inflation progression, the inflated shape and the internal pressure of the airbag. A drop tower test of the airbag measured the force-crush and energy absorbing characteristics of the airbag. The knee bolster assembly consists of two components. Separate quasistatic tests of the aluminum honeycomb and the knee bolster bracket measured the force-crush and energy absorbing characteristics. The component test results were used to improve the computer model and permit analysis of the entire system.

This paper discusses the prototype design, including background research, baseline definition and prototype development. The initial prototype design is analyzed using computer models. The components are tested to verify and improve the computer models. The test and analysis results are presented. Future work is planned for fabrication of the cab desk and prototype system to be used in a sled test with a $95^{\text {th }}$ percentile ATD.

\section{INTRODUCTION}

Current cab designs have minimal interior crashworthy features. The clean cab concept from the 1970s removes sharp edges and protruding objects from the cab. While this is an improvement for very low speed collisions, a more rigorous protection system is necessary for higher speeds. This research focuses on protecting the engineer in higher speed collisions, considering the availability of modern, state-of-the-art occupant protection methodologies.

"This material is declared a work of the U.S. Government and is not subject to copyright protection in the United States. Approved for public release; distribution is unlimited." 


\section{BACKGROUND}

Design requirements are implemented to ensure, to the extent possible, that the prototype design will be acceptable to car builders, maintenance departments, and cab engineers. The prototype design must fit into a typical cab car geometry layout without hindering the functionality of the cab. The layout must not interfere with normal activities of the engineer, taking into account human factors concerns. The cab must be kept free of any sharp or protruding objects in accordance with the clean cab concept.

The prototype design is required to allow for quick egress of the engineer. The final design cannot use a seatbelt, as engineers want the ability to run from the cab unencumbered in the event that an unavoidable collision is imminent. The system has to be entirely passive, such that the engineer would not need to do anything to trigger the protective system. Passive trigger mechanisms must be designed so that protection devices are not deployed prematurely or accidentally.

The occupant protection requirements are measured by performing a sled test and analyzing the results. The sled test includes the cab design and protection system, a $95^{\text {th }}$ percentile ATD and a specified acceleration pulse. When the sled and the ATD are subjected to the acceleration pulse, the ATD must be compartmentalized and the injury criteria must not exceed the specified limits.

The cab operator test pulse, Figure 1, is representative of that experienced by the front end of a rail car during a collision. The front end of a rail car is subjected to the most severe pulse during a collision, due to its proximity to the collision interface. For this acceleration pulse, the acceleration increases from 0 to $23 \mathrm{~g}$ in $0.01 \mathrm{~s}$, maintains an acceleration of $23 \mathrm{~g}$ for $0.02 \mathrm{~s}$ and then decreases to $0 \mathrm{~g}$ over $0.1 \mathrm{~s}$. The secondary impact velocity was calculated from this acceleration curve and plotted in Figure 2 as the "Cab Operator Test Pulse". The next section compares the secondary impact velocity (SIV) of the test pulse to other known pulses.

\section{Secondary Impact Velocity}

The SIV refers to the speed, relative to the rail car, with which an occupant's body (considered as a point mass) impacts part of the interior, such as the cab console. The SIV is calculated by integrating the acceleration-time history once to calculate the velocity of the occupant, and integrating a second time to calculate the position of the occupant. The position and the velocity are plotted against one another. SIV can be minimized by limiting the longitudinal travel distance between an occupant and an interior fixture, because SIV generally increases with distance traveled.

The cab operator test acceleration pulse has an SIV similar to the SIV from the multi-level single car test [2]. In this test, a single car impacted a fixed wall at 36.6 miles per hour. The multilevel car has a very strong underframe resulting in a rapid deceleration and a severe SIV at a relatively low collision speed. This car is a good example of a car with increased crashworthiness that preserves the space for the engineer at a higher speed but subjects the engineer to a severe deceleration pulse.

Several other calculated SIV curves are shown in Figure 2. The SIV for the $8 \mathrm{~g}, 250 \mathrm{~ms}$ triangular pulse is taken from the American Public Transportation Association Seat Standard [3]. The $12 \mathrm{~g}, 250 \mathrm{~ms}$ triangular pulse was the design requirement for the rear facing commuter seats in the crash-energy management train-to-train test [4]. Rail Safety and Standards Board (RSSB) recently released its "Requirement for Structural Vehicles", GM/RT2100 Issue 4, that contains a crash pulse specification for interior seats and tables [5]. RSSB publishes and maintains safety standards for trains operating in Great Britain. The SIV measured in the cab of the lead car in the full scale crash energy management train-to-train test is included in the figure. This is a particularly harsh pulse because the crush zone elements were between the cab and the car body [6]. The SIV from a typical automobile crash pulse is also included in the figure. The figure shows that the test pulse chosen for this project is not unlikely in a moderate speed train collision, and within the bounds of SIV experienced by automobile occupants.

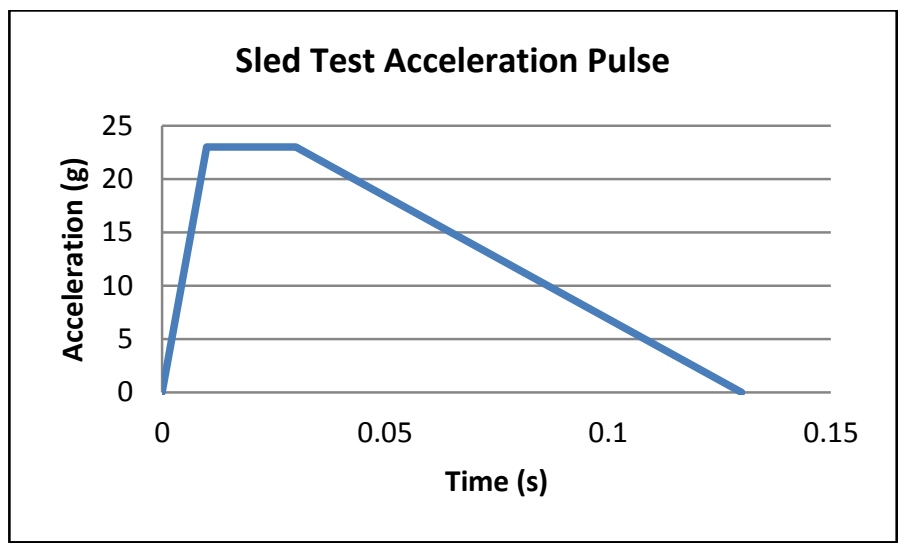

Figure 1. Specified Sled Test Acceleration Pulse for Engineer Protection System

"This material is declared a work of the U.S. Government and is not subject to copyright protection in the United States. Approved for public release; distribution is unlimited." 


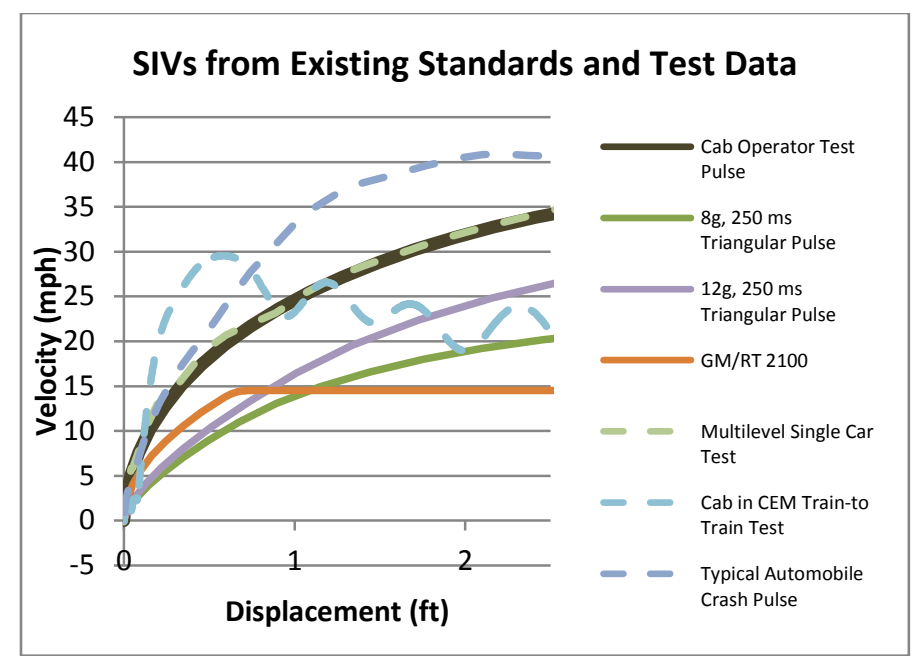

Figure 2. SIV curves from existing rail standards and equipment

\section{Injury criteria}

Injury criteria for impacts with the interior surfaces exist in the form of internationally accepted standards for the head, neck, chest, femur and other areas of the body. The following injury criteria chosen for this prototype were derived from the Federal Motor Vehicle Safety Standards [1]. The American Public Transportation Association's Standard for Passenger Seats in Passenger Rail Cars uses these values [3]. Other injury criteria can be found in GM/RT2100 Issue 4, Structural Requirements for Railway Vehicles, Appendix H [5]. Table 1 shows the injury criteria used and the abbreviations used later in this paper.

Table 1. Injury Criteria and Abbreviations

\begin{tabular}{|l|l|}
\hline Name & Abbreviation \\
\hline Head Injury Criteria & HIC 15 \\
\hline Chest Acceleration & Chest 3ms \\
\hline $\begin{array}{l}\text { Femur Injury Criteria (left and } \\
\text { right leg) }\end{array}$ & Femur Left, Femur Right \\
\hline Neck Injury Criteria (Nij) & NTE \\
- Neck Tension-Extension & NTF \\
- Neck Tension-Flexion & NCE \\
- Neck Compression-Extension & NCF \\
\hline - Neck Compression-Flexion & Neck Compression \\
& Neck Tension \\
\hline
\end{tabular}

\section{BASELINE CAB GEOMETRY}

Several cab layouts were reviewed to determine reasonable dimensions and layout for the baseline cab to incorporate the prototype design. Cab layouts were surveyed in the following equipment: Long Island Railroad (LIRR) cab car manufactured by Kawasaki Heavy Industries, Ltd; a METRA (Chicago) cab car manufactured by Nippon Sharyo; a METROLINK cab car manufactured by Bombardier, Inc; and a NICTD electric multiple unit cab car manufactured by Nippon Sharyo. For each cab layout, specific dimensions, such as console height, width and thickness, were measured. A summary of the dimensions measured from the existing cabs and defined for the baseline cab is shown in Table 2.

Table 2. Cab Layout Measurements

\begin{tabular}{|l|c|c|c|c|c|}
\hline & LIRR & Metra & $\begin{array}{c}\text { Metro } \\
\text {-link }\end{array}$ & NICTD & Baseline \\
\hline $\begin{array}{l}\text { Chair base } \\
\text { column to } \\
\text { edge of } \\
\text { control desk }\end{array}$ & $18.5 "$ & $13.5 "$ & $14 "$ & $13.5 "$ & 13.5 \\
\hline $\begin{array}{l}\text { Desk Edge } \\
\text { Thickness }\end{array}$ & $\begin{array}{c}2.75 \\
\text { and } \\
5.5 "\end{array}$ & $2.25 "$ & $\begin{array}{c}1 " \\
\text { and } \\
5 "\end{array}$ & $2.25 "$ & $2.25 "$ \\
\hline $\begin{array}{l}\text { Height of } \\
\text { desk leading } \\
\text { edge from } \\
\text { floor }\end{array}$ & $29.5 "$ & $30 "$ & $\begin{array}{c}26.5 " \\
\text { and } \\
30.63 \\
"\end{array}$ & $30 "$ & $30 "$ \\
\hline $\begin{array}{l}\text { Desk depth - } \\
\text { Window wall } \\
\text { to leading } \\
\text { edge }\end{array}$ & $18.5 "$ & $24 "$ & $19 "$ & $24 "$ & $24 "$ \\
\hline
\end{tabular}

The architecture of the baseline cab uses layout features from all of the measured cab designs. Table 3 shows how the baseline cab architecture compares to existing designs. The goal was to design a baseline console that would provide an adequate representation of existing designs without being an exact replica of one particular design. A schematic of the baseline design with a $95^{\text {th }}$ percentile ATD is shown in Figure 3.

Table 3. Baseline Cab Desk Architecture

\begin{tabular}{|l|l|l|}
\hline Feature/Item & Location & $\begin{array}{l}\text { Selected Style } \\
\text { Basis }\end{array}$ \\
\hline Throttle \& Reverser & Right & Metrolink \\
\hline Brake Control Lever & Left & Metrolink \\
\hline $\begin{array}{l}\text { Telephone/Radio } \\
\text { Cradle }\end{array}$ & Left & $\begin{array}{l}\text { LIRR, Metrolink, } \\
\text { Metra }\end{array}$ \\
\hline Console Location: & & \\
\hline \multicolumn{1}{|c|}{ Overhead } & Yes & $\begin{array}{l}\text { LIRR, Metra, } \\
\text { Metrolink, NICTD }\end{array}$ \\
\hline \multicolumn{1}{|c|}{ Right } & No & $\begin{array}{l}\text { LIRR, Metra, } \\
\text { Metrolink, NICTD }\end{array}$ \\
\hline \multicolumn{1}{|c|}{ Left } & Yes & $\begin{array}{l}\text { LIRR, Metrolink, } \\
\text { NICTD }\end{array}$ \\
\hline $\begin{array}{l}\text { Foot Operated } \\
\text { Switch }\end{array}$ & Left & $\begin{array}{l}\text { LIRR, Metrolink, } \\
\text { NICTD }\end{array}$ \\
\hline
\end{tabular}

"This material is declared a work of the U.S. Government and is not subject to copyright protection in the United States. Approved for public release; distribution is unlimited." 
In addition to this cab survey, a report on "The Human Factors Guidelines for Locomotive Cabs" recommends that the train motion controls be placed directly in front of the engineer with the brake module on the left [7]. While this baseline design is for a cab car, not a locomotive, the brake and the throttle and reverser are placed accordingly.

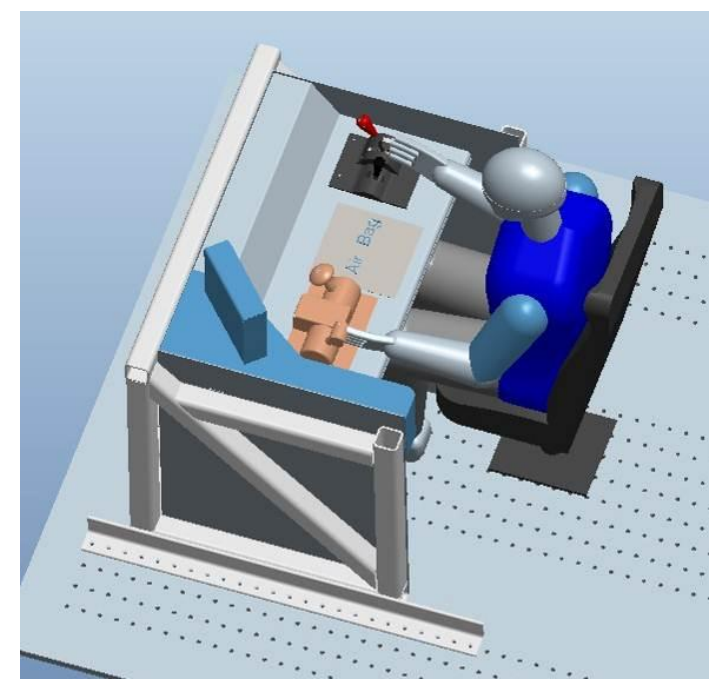

Figure 3. Baseline cab design with $95^{\text {th }}$ percentile ATD.

\section{PROTOTYPE DESIGN}

Several options were researched for the protection system. For the baseline cab, the ATD impacts the thin desk edge at the abdomen and impacts the underside of the table with the knees. The ATD body then rotates around the desk edge, hitting the head on the top of the console. During the head strike, the neck is rotated sharply backwards. The prototype system design needs to protect the abdomen, head, neck and knees/femurs. Ultimately, an airbag and a deformable knee bolster were chosen to protect the ATD. Also considered were inflatable tubular structures, a knee airbag, and a crushable console. Early analysis demonstrated that the inflatable tubular structure and the knee airbag were feasible designs. The crushable console was not a workable solution as it did not provide adequate protection to the occupant. Inflatable tubular structures are explored in previous research performed on locomotive cabs [8].

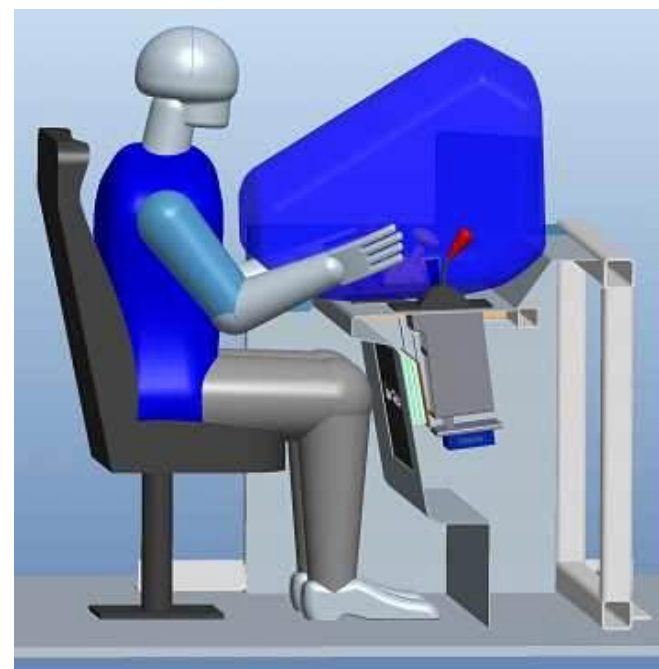

Figure 4. Initial prototype design layout

The initial design ideas were simulated using the computer program MAthematical DYnamic MOdels (MADYMO) [9]. MADYMO has both multi-body and finite element features that allow for calculation of occupant injury criteria. For the initial models, the ATD and the cab console were modeled as lumped masses and springs. The airbag was modeled using the finite element (FE) method. In this lumped parameter MADYMO model the knee bolster has a user defined force-displacement characteristic.

Figure 5 shows the kinematics of the ATD and the protection system. At the beginning of the crash pulse, the ATD slides forward and the airbag deploys. Contact occurs between the knees and the knee bolster and the head, chest and airbag at the same time. The ATD's knees push into the bolster and energy is absorbed there. At the same time the ATD is pitching forward and the legs are straightening out. The airbag restrains the head, neck and chest of the dummy. The airbag and the knee bolster contain the ATD's motion to remain in the longitudinal direction. The airbag allows for safe deceleration of the head, neck and chest, and the knee bolster limits the force applied to the knees and femurs during deceleration.

"This material is declared a work of the U.S. Government and is not subject to copyright protection in the United States. Approved for public release; distribution is unlimited." 

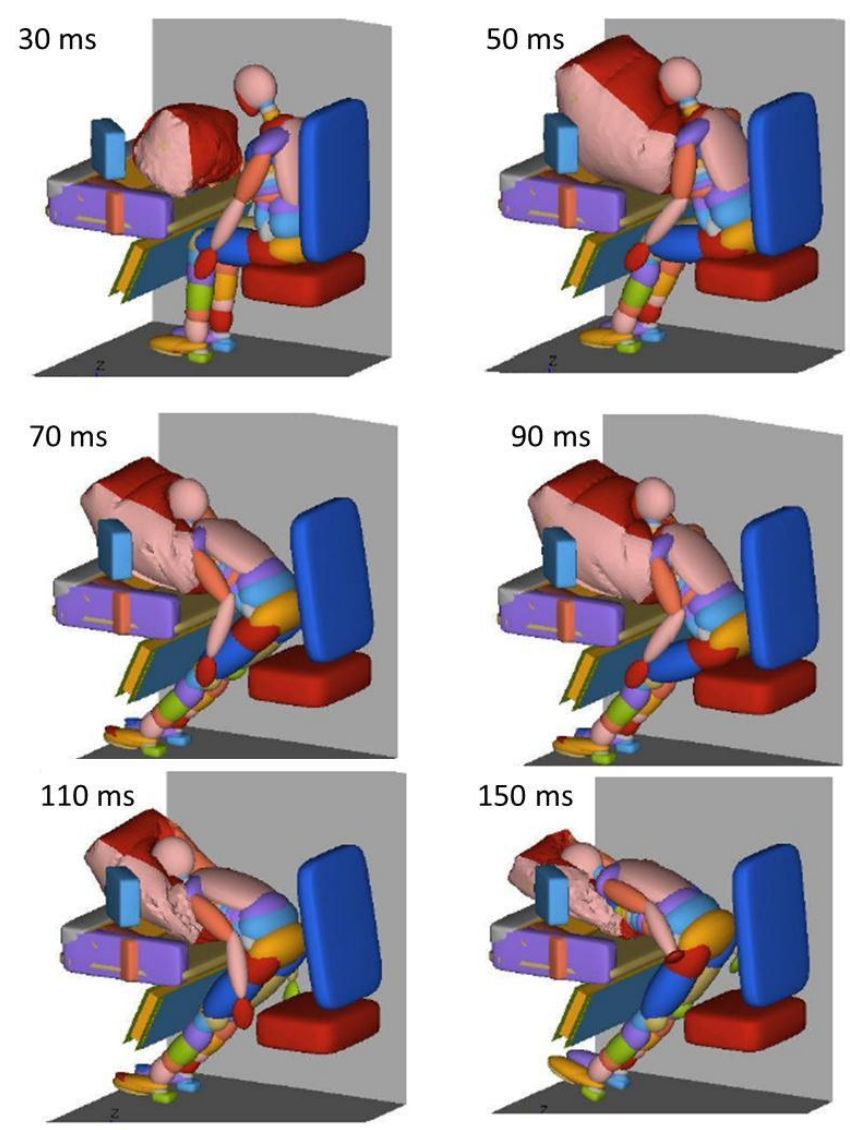

Figure 5. Dummy kinematics in MADYMO

In addition to the hybrid FE and lumped parameter model built in MADYMO, additional simulations were performed with a full FE model built in Radioss [10]. The Radioss model allows for the dummy and the knee bolster to be modeled with finite elements. It also provides a check for the MADYMO Model. The results are compared in

Table 4. The baseline case was run in MADYMO with the baseline cab model and no occupant protection system. For the kinematics of the baseline case, the dummy hits the front window at a significant speed resulting in a very high acceleration. All this secondary crash pulse energy is absorbed by the head, neck and femurs. The pulse is so severe that the injury limits are greatly exceeded for the Head Injury Criteria (HIC_15) the axial femur load, and for the axial neck tension values. Further details on these injury criteria can be found in FMVSS 208 [1].

The prototype system was analyzed using both MADYMO and Radioss computer analysis programs. Both the MADYMO and the Radioss models produce the same kinematics described in Figure 5. One key difference between the two models is that the airbag is modeled differently with each FE tool. The airbag in the MADYMO model is slightly more permeable, allowing for a late head strike with the console and resulting in a higher HIC. In the RADIOSS model, the airbag leakage and deflation timing were tuned to avoid that head strike, resulting in a lower HIC. During the prototype model development stage these differences were not explored in further detail, since both models predicted that the airbag would provide adequate protection. Both airbag models were refined after airbag component testing.

Table 4 compares the baseline results with both the Radioss and the MADYMO models. With the prototype system, results from both models suggest that the injury criteria will not exceed the acceptable limits. While the MADYMO and the Radioss models do not produce exactly the same results, they are reasonably close with the exception of the HIC value. The MADYMO model predicts a harsher HIC of 623 than the 125 value predicted by Radioss, as a result of the differences in the airbag models.

Table 4. Injury results for the baseline cab and the prototype system

\begin{tabular}{|l|l|l|l|l|}
\hline $\begin{array}{l}\text { Injury } \\
\text { Response }\end{array}$ & Limit & $\begin{array}{l}\text { Baseline - } \\
\text { MADYMO }\end{array}$ & $\begin{array}{l}\text { Prototype } \\
\text { system - } \\
\text { MADYMO }\end{array}$ & $\begin{array}{l}\text { Prototype } \\
\text { System - } \\
\text { RADIOSS }\end{array}$ \\
\hline HIC_15 & 700 & 9,661 & 623 & 125 \\
\hline $\begin{array}{l}\text { Chest 3ms } \\
\text { (g) }\end{array}$ & 60 & 38 & 43 & 37 \\
\hline $\begin{array}{l}\text { Femur Left } \\
(\text { N) }\end{array}$ & 10,000 & 20,307 & 5,932 & 7,485 \\
\hline $\begin{array}{l}\text { Femur } \\
\text { Right (N) }\end{array}$ & 10,000 & 20,236 & 5,929 & 7,745 \\
\hline $\begin{array}{l}\text { Neck } \\
\text { Tension } \\
\text { N) }\end{array}$ & 4,170 & 5,089 & 2,754 & 2,193 \\
\hline $\begin{array}{l}\text { Neck } \\
\text { Comp. (N) }\end{array}$ & 4,000 & 2,525 & 94 & 789 \\
\hline NTE & 1 & 1.39 & 0.59 & 0.64 \\
\hline NTF & 1 & 1.07 & 0.55 & 0.29 \\
\hline NCE & 1 & 0.28 & 0.16 & 0.23 \\
\hline NCF & 1 & 0.82 & 0.03 & 0.24 \\
\hline
\end{tabular}

As with any rolling stock design component, the added weight of any new component needs to be taken into consideration. The total weight of the knee bolster and the airbag combined is under $30 \mathrm{lb}$. This weight is negligible when compared to the weight of an entire cab car. Table 5 breaks down the weight of the components. The knee bolster is broken into components and the components are shown in grey. It is possible that some additional structure would need to be added to the control desk, so that the knee bolster and the airbag are supported properly during a collision. This additional structure would not be substantial when compared to the overall weight of the car.

"This material is declared a work of the U.S. Government and is not subject to copyright protection in the United States. Approved for public release; distribution is unlimited." 
Table 5. Prototype System Weight

\begin{tabular}{|l|l|}
\hline Component & Weight, lb \\
\hline Knee Bolster Components & \\
\hline Brackets & 7.4 \\
\hline Back Plate & 8.8 \\
\hline Honeycomb & 0.9 \\
\hline Front Plate & 2.7 \\
\hline Knee Bolster Total & 19.8 \\
\hline Airbag & 8.6 \\
\hline Total & 28.4 \\
\hline
\end{tabular}

\section{Airbag and Inflator}

The role of the airbag is to arrest the motion of the engineer during a collision so the head, neck, and torso do not hit a very hard surface, the cab console. The airbag also decreases the distance that the ATD has to travel before impact. The airbag will decelerate the engineer in a manner that will limit injuries to the head neck and chest. The airbag is also designed to help control the kinematics of the ATD deceleration.

The airbag designed for this application is a slight variation on an automotive passenger side (as opposed to driver's side) airbag. A typical passenger-style airbag has a volume of 120140 liters. The airbag designed for this project has a length of $700 \mathrm{~mm}(27.5 \mathrm{in})$, a width of $450 \mathrm{~mm}$ (17.7 in) and a maximum inflated volume of 155 Liters $\left(5.5 \mathrm{ft}^{3}\right)$. The airbag design can be easily manufactured using existing proven airbag manufacturing techniques. The other components of the airbag system (the control module and acceleration sensor, the trigger, and the housing for the folded airbag) are off-the-shelf items and not designed specifically for this application. The inflator is a KSS Model PH-5, single or dual stage, $700 \mathrm{KPa}$ inflator. The control module, which triggers the airbag and controls the inflator, takes input from two accelerometers at the front of the car, similar to how such a trigger works in an automobile. The trigger threshold values would have to be adjusted for each specific car design, and therefore are not explored in great detail for this project. The details of the trigger design will be presented in future research results. The weight of the airbag system, including airbag, housing, and inflator is about $6.6 \mathrm{lb}$.

Two versions of the airbag were analyzed and tested for this program. One bag has two $10 \mathrm{~mm}$ vents and the other does not have any vents. Other features were identical. Venting is usually designed into the airbag based on the required deflation time, which is application specific. Train collisions have a longer deceleration pulse than an automobile crash. Analyses have shown that the bag needs very small $10 \mathrm{~mm}$ vents, or possibly no vents at all to adequately protect the occupant.

\section{Knee Bolster}

The knee bolster design has two energy absorbing components, a deformable bracket, and a four inch thick crushable aluminum honeycomb. The knee bolster design is shown in Figure 6. The figure shows the back view of the bolster. The front of the cab, where the knees would hit, is on the other side of the yellow console plate. The aluminum honeycomb is green, the supporting plate for the honeycomb is red, the deformable brackets are dark blue and light blue. The light blue part of the bracket will be welded to the underside of the control table.

The function of the knee bolster is to limit the deceleration forces to the occupant. The key measurement in determining if the knee bolster is functioning as intended is the femur load. In this design, the honeycomb crushes and the support bracket deforms. Both the honeycomb and the bracket absorb energy in a controlled fashion. The bracket and the honeycomb were quasi-statically testing as part of this program.

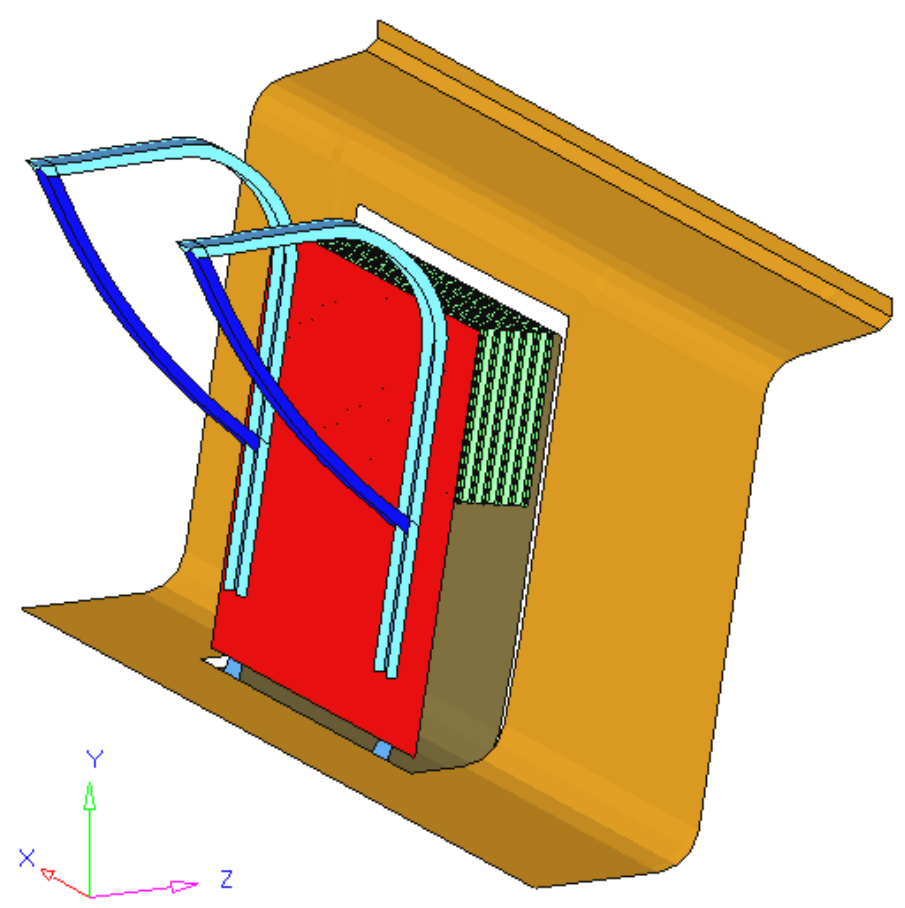

Figure 6. Knee Bolster design

The force-crush characteristic of the knee bolster limits the force on the occupant. The design values from preliminary FE models are shown in Figure 7. This is the force crush characteristic as seen by one simulated knee. For one knee, the bolster has a crush force increasing from 800 to $1,600 \mathrm{lb}$ over a distance of 4.25 inches. The energy absorbed is approximately $5000 \mathrm{in}-\mathrm{lb}$. The component tests were performed to characterize the specific design elements, which would be used to confirm design performance.

"This material is declared a work of the U.S. Government and is not subject to copyright protection in the United States. Approved for public release; distribution is unlimited." 


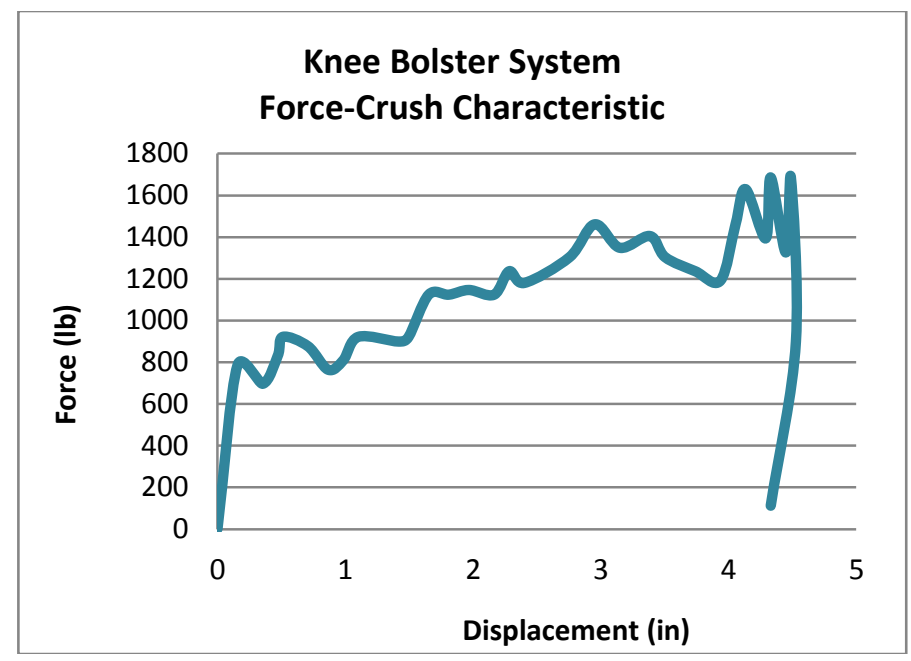

Figure 7. Preliminary Knee Bolster force-displacement characteristic from FE model for one knee

\section{COMPONENT TESTING}

Four different tests were conducted on the components of the engineering protection system. A static deployment test and a drop tower test were performed on the airbag. Quasi-static loading tests were performed separately on the knee bolster bracket and aluminum honeycomb. Component tests measured the key characteristics of the airbag and the knee bracket and provided test data necessary to validate the analyses.

\section{Airbag Static Deployment Test}

The airbag static deployment test was conducted to establish the airbag's deployed shape, deployment height and overall bag integrity. The test establishes the height of the fully deployed airbag and confirms that the internal tethering works as intended. The airbag system is composed of the airbag and the inflator, which are both housed in a standard automotive packaging format. The proposed system uses an automotive 'passenger-style' airbag and an off-the-shelf inflator. Two tests were conducted on the two different airbag designs.
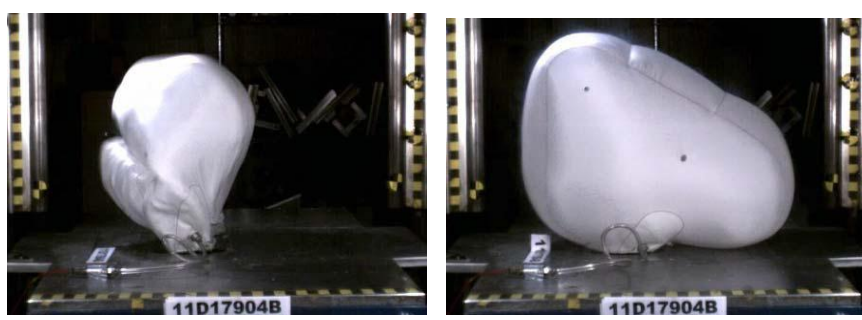

Figure 8. Airbag kinematics during the static deployment test

After the test, the video was examined to determine the fully inflated height of the airbag, and to determine if the tethering worked as intended so that the deployed shaped was as expected. The pressure signal data confirmed that there were no anomalies and the airbag maintained adequate pressure throughout deployment. Also, after the test, the airbag was inspected to ensure that it retained its integrity and did not have any tears or separated seams.

\section{Airbag Drop Tower Test}

The airbag drop tower test was conducted to measure the force-displacement behavior of the airbag. This information is used to refine the airbag finite element model. During this test sequence, a known mass is dropped from a defined height onto a fully inflated airbag that is triggered and deployed during the test. The dropped mass, $80 \mathrm{lbs}$, is the standard mass used to represent a $95^{\text {th }}$ percentile ATD in automotive tests. While the crash pulse for a train collision is different from that of an automobile collision, the kinematics of the ATD hitting the airbag are similar. This energy input value is calculated from prior MADYMO simulations of the proposed concept for a 95th percentile male ATD under a 23g, 130 ms deceleration pulse. Figure 9 shows still photographs from the high speed test video. In the top left photo, the airbag is still inflating. In the top right photo, the airbag is nearly fully inflated and the mass has not yet contacted the airbag. In the bottom two photos, the mass is impacting the airbag and the airbag is absorbing the kinetic energy of the mass. After the photo in the bottom right, the mass is completely stopped and rebounds slightly before it finally reaches the floor. Subsequently, the dropped mass gently reached the floor as the last of the air escaped from the airbag The drop tower airbag test was completed a total of four times, two for each airbag type (vented and unvented). The test and test results, particularly the accelerometer data, were found to be repeatable.
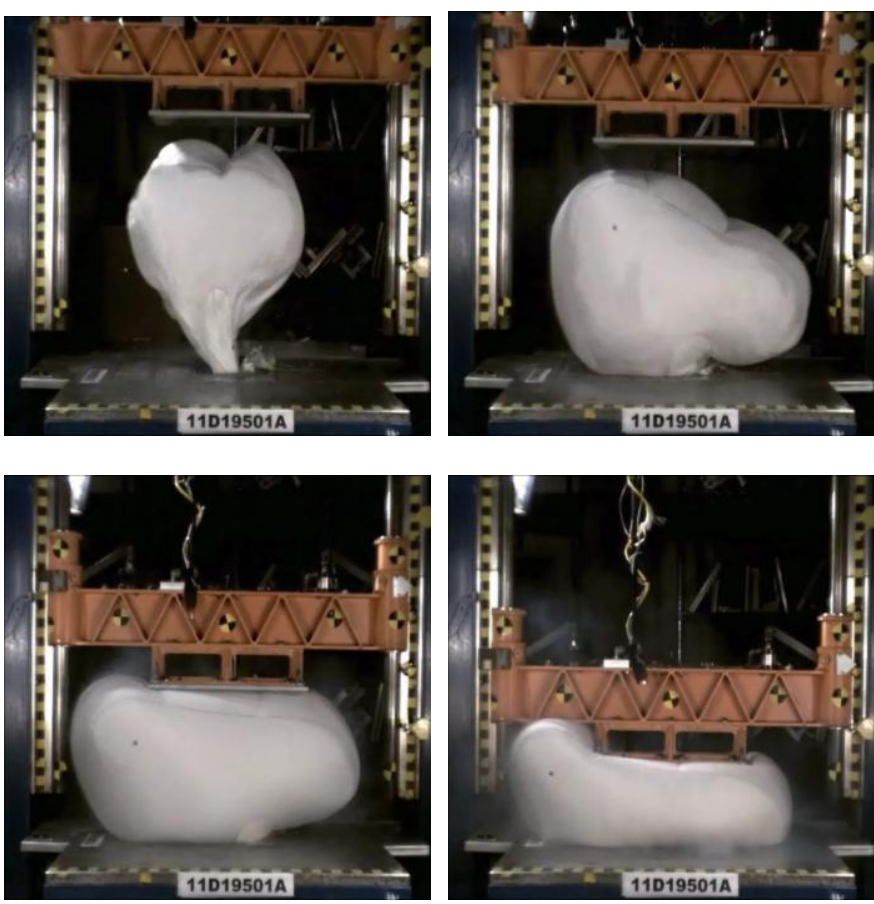

Figure 9. Drop tower airbag test

"This material is declared a work of the U.S. Government and is not subject to copyright protection in the United States. Approved for public release; distribution is unlimited." 
The results from the drop tower tests and the refined model are shown in Figure 10 and Figure 11. The force-displacement characteristic is derived from accelerometers mounted on the dropped mass. The velocity of the mass at the start of the data acquisition system is calculated, and might slightly vary based on the friction of the drop tower. The unvented airbag results in Figure 10 show that the airbag crushes approximately 15 inches. The height of the airbag is initially 23 inches. However, as shown in the bottom right photo in Figure 9, the height of the airbag has been reduced to approximately 8 inches when the kinetic energy of the mass has been dissipated. The Radioss and MADYMO models show good agreement with the test results. The Radioss model does have some large oscillations due to minor model differences and the way in which the acceleration results are reported, but these differences are not expected to have an effect in the sled test model and resulting injury criteria, and overall the average force level and the displacement have good agreement.

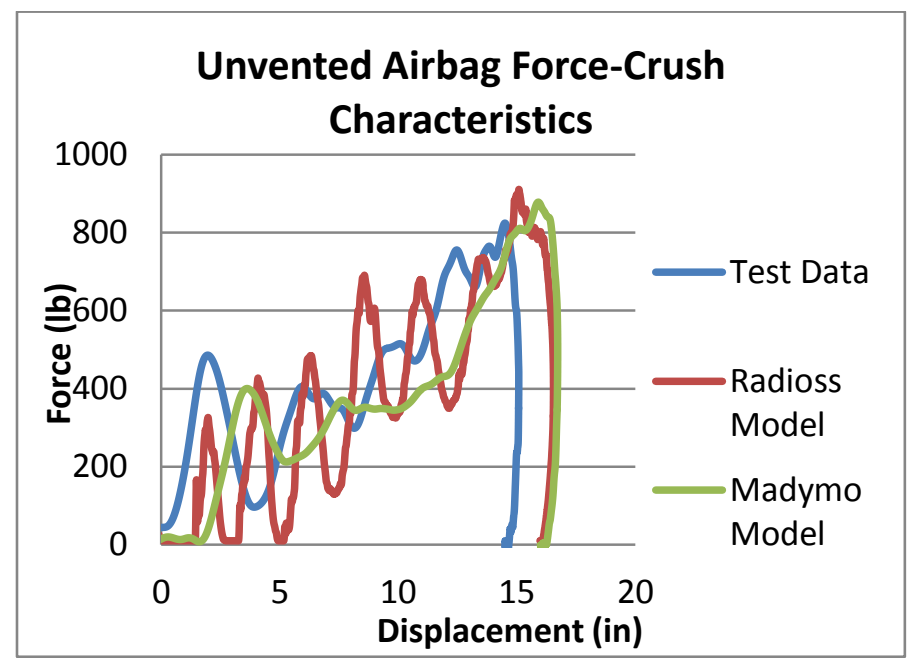

Figure 10. Unvented airbag force-displacement characteristic test and model comparison

The vented airbag results shown in Figure 11 also indicate approximately 15 inches of crush. Reasonable agreement is seen here between the test data and the Radioss Model. The airbag in the MADYMO model is a little soft here. For both the unvented and the vented versions of the airbag, the differences in modeling are due to how the leakage properties of the airbag are taken into account.

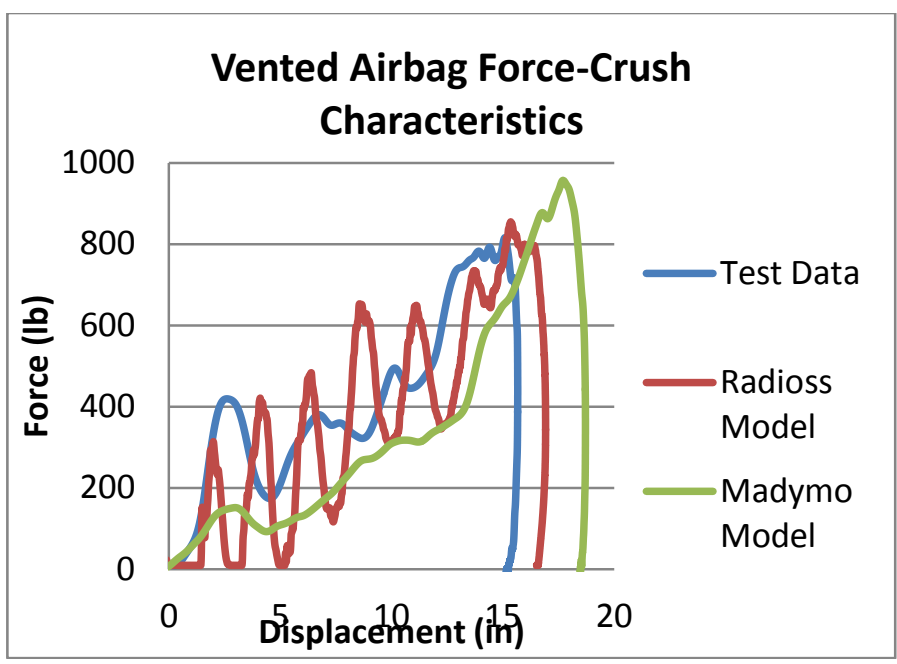

Figure 11. Vented Airbag force-displacement characteristic test and model results comparison

The drop tower mass has an initial height of 89". The mass is stopped approximately 8 inches above the floor. Since the crucial performance of the airbag occurs in the first 15 inches of crush, only those data are recorded and shown here. The bulk of the energy of the dropped mass is absorbed within the first 15 inches. After 15 inches, the mass rebounds slightly and then the slowly falls to the ground as the remaining air in the airbag dissipates. For a total displacement of 81 " and a mass of $80 \mathrm{lb}$, the energy absorbed is $6,480 \mathrm{in}-\mathrm{lb}$. Figure 12 compares the energy absorption of the unvented and vented airbags, calculated from the dropped mass accelerometer data. The vented airbag absorbs 6,457 in-lb and the unvented airbag absorbs $6,395 \mathrm{in}-\mathrm{lb}$. The vented airbag displaced slightly more than the unvented airbag. The vented airbag is expected to be "softer" than the unvented airbag, so slightly more displacement is expected.

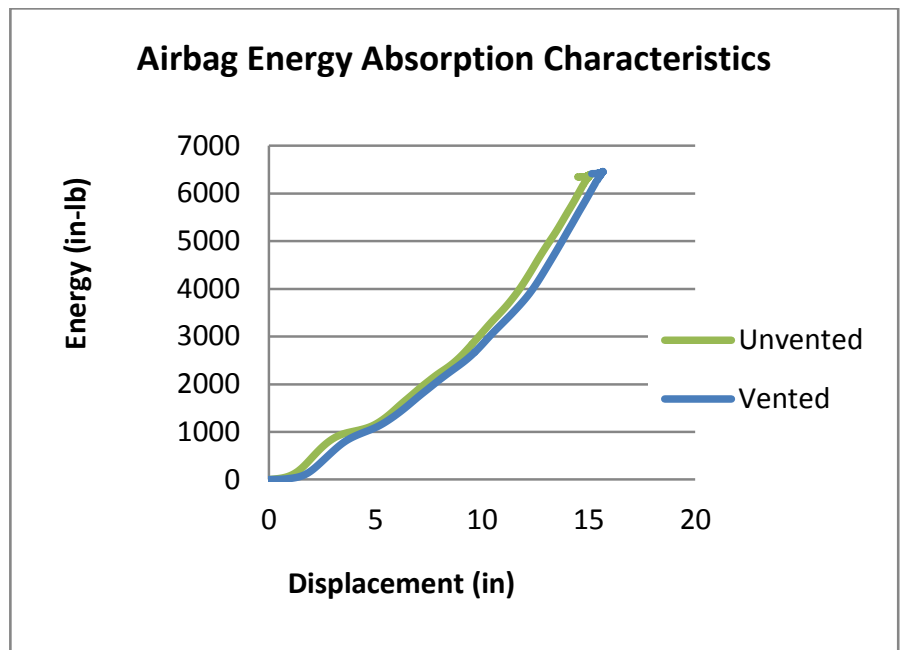

Figure 12. Energy Absorption Comparison: Unvented and Vented Airbag

"This material is declared a work of the U.S. Government and is not subject to copyright protection in the United States. Approved for public release; distribution is unlimited." 


\section{Knee Bolster Bracket Quasi-Static Test}

The bracket in the knee bolster system was tested in a quasistatic manner to measure/characterize its force-deflection characteristics. The bracket was oriented sideways, as shown in Figure 13. The welds that would connect the bracket to the underside of the table are on the left side of the photo. The indenter, representing the location where the force from the knee would impact the bracket, is oriented vertically. During the test, the load was increased slowly so that there were no dynamic effects. The displacement and the force of the hydraulic ram were measured. Figure 14 compared the forcedisplacement characteristics of the first and second test. Each test was conducted on a single bracket. There are two brackets in the full knee bolster design. The knee bracket deformed in a controlled fashion. The force level was maintained at slightly higher than $700 \mathrm{lb}$ for three inches. After the tests, the brackets were inspected and no cracks were found. Figure 15 shows the energy absorption of the two brackets. The energy absorption values were very close, approximately $2,900 \mathrm{in}-\mathrm{lb}$.
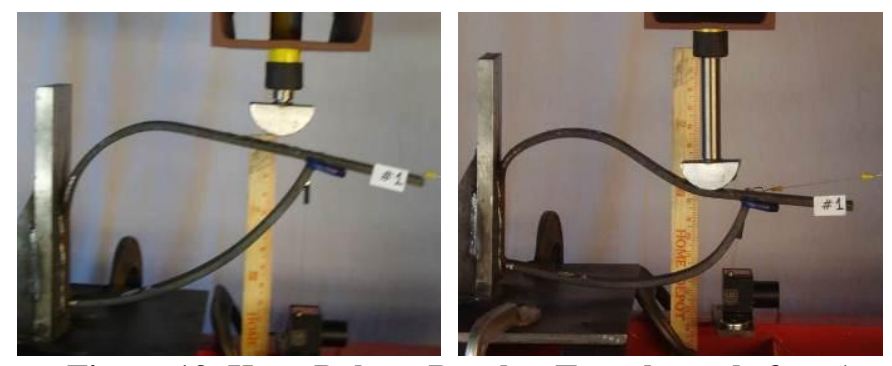

Figure 13. Knee Bolster Bracket Test photos before (top) and after the quasi-static deformation test

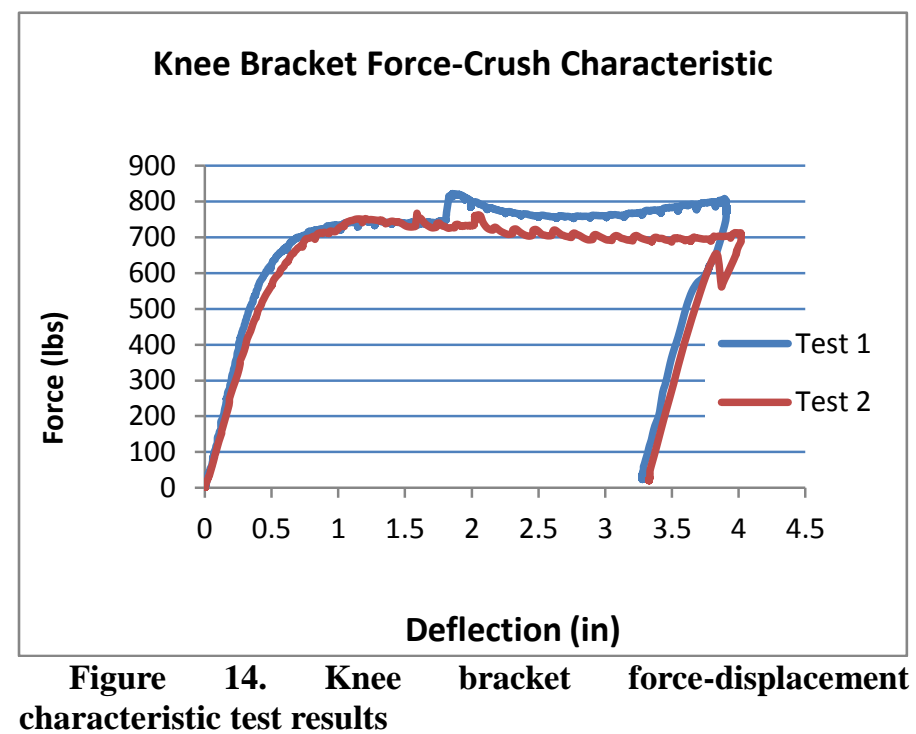

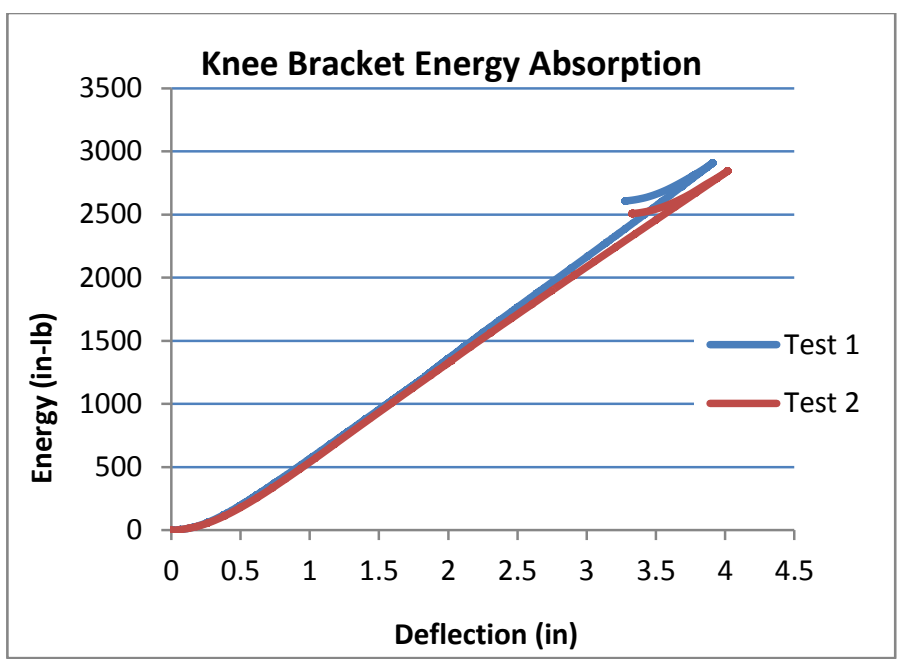

Figure 15. Knee bracket energy absorption test results

\section{Honeycomb Quasi-static Tests}

Aluminum honeycomb is used as part of the knee bolster. The test specimen was composed of four stacked sheets of $5 / 8$ " thickness each with a cross section of 4" 4 ". The honeycomb material is model \#HexWeb CRIII-3/8-5052-0015N-2.3, manufactured by HexCel Corp. The material is composed of $3 / 8$ " hexagonal cells made of 5052 Aluminum with a nominal foil thickness of 0.0015 ". The engineered crush strength of the honeycomb is 75 psi. For a 4 " $x 4$ " cross section, this specimen should have a nominal crush force of 1,200 lb.

The four stacked sheets were placed between rigid steel plates. The load was introduced in a quasi-static fashion with a hydraulic ram. The load was measured with a load transducer and the displacement was measured with a string potentiometer. Figure 16 shows the honeycomb test specimen before, during and after the quasi-static test. The photos show that the honeycomb layers did not crush uniformly. The forcedisplacement results, Figure 17, show that the honeycomb assembly does crush with a uniform force of approximately $1,000 \mathrm{lb}$. This is slightly lower than the design value and will be accounted for in the final bolster design. The two test specimens have very similar results.

The energy absorption results, Figure 18, show very similar energy absorption between the two samples. The energy absorption is approximately 2,300 in-lb. The combined energy absorption of one stack of honeycomb and one knee bracket is $5,200 \mathrm{in}-\mathrm{lb}$. This achieves the original knee bolster design target of 5,000 in-lb. The honeycomb and the bracket combined limit the force to the femur to acceptable levels.

"This material is declared a work of the U.S. Government and is not subject to copyright protection in the United States. Approved for public release; distribution is unlimited." 

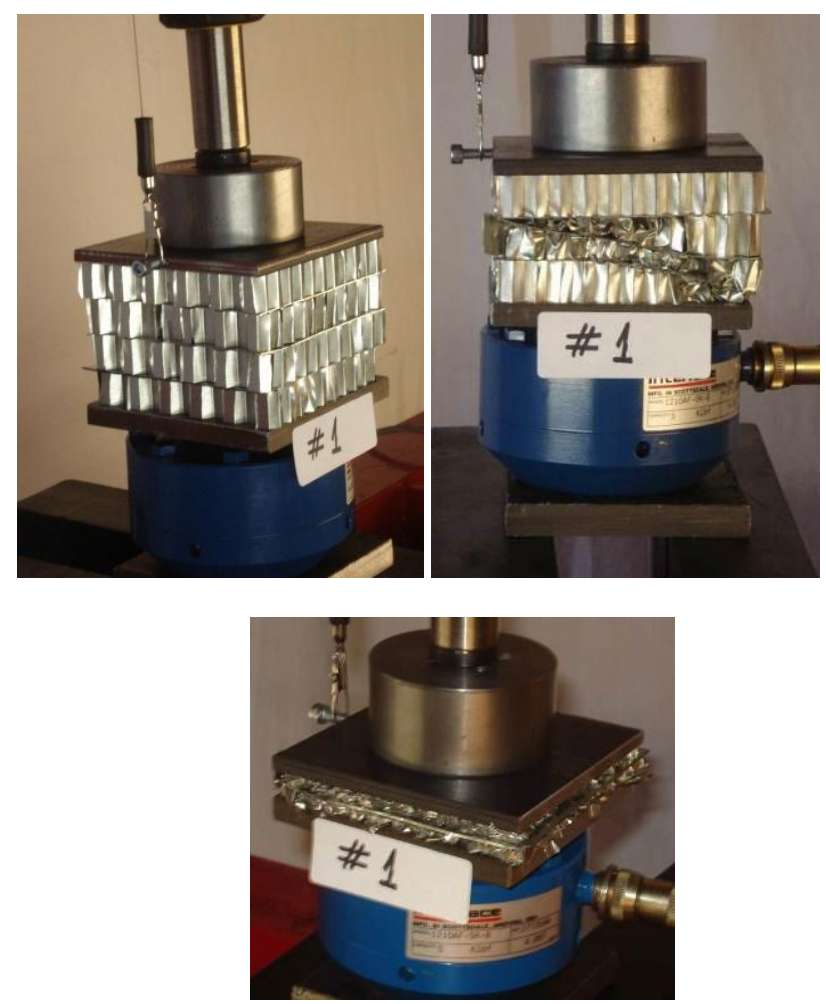

Figure 16. Honeycomb test specimen before, during and after the quasi-static test

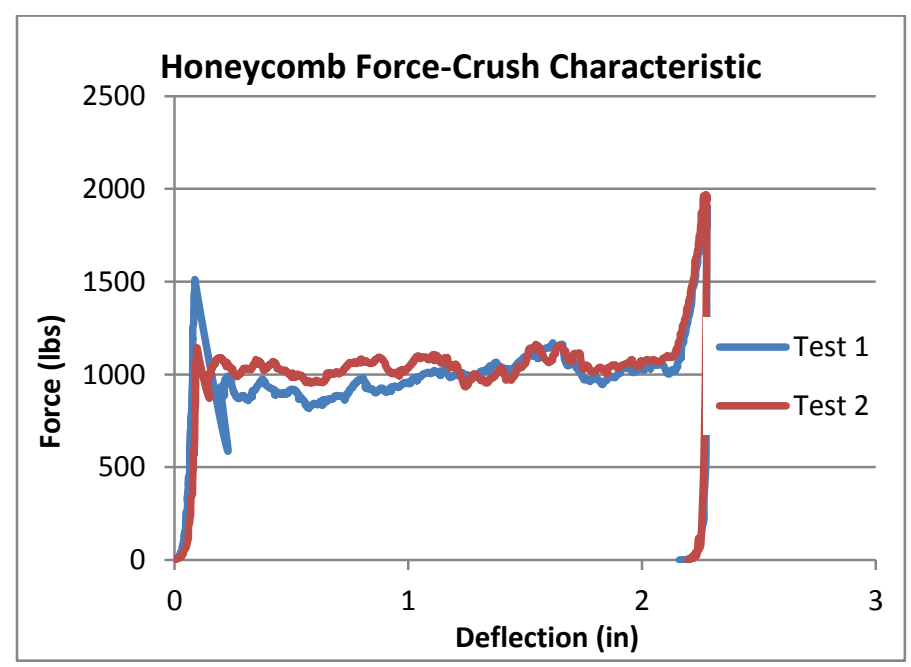

Figure 17. Honeycomb Force-displacement characteristic test results

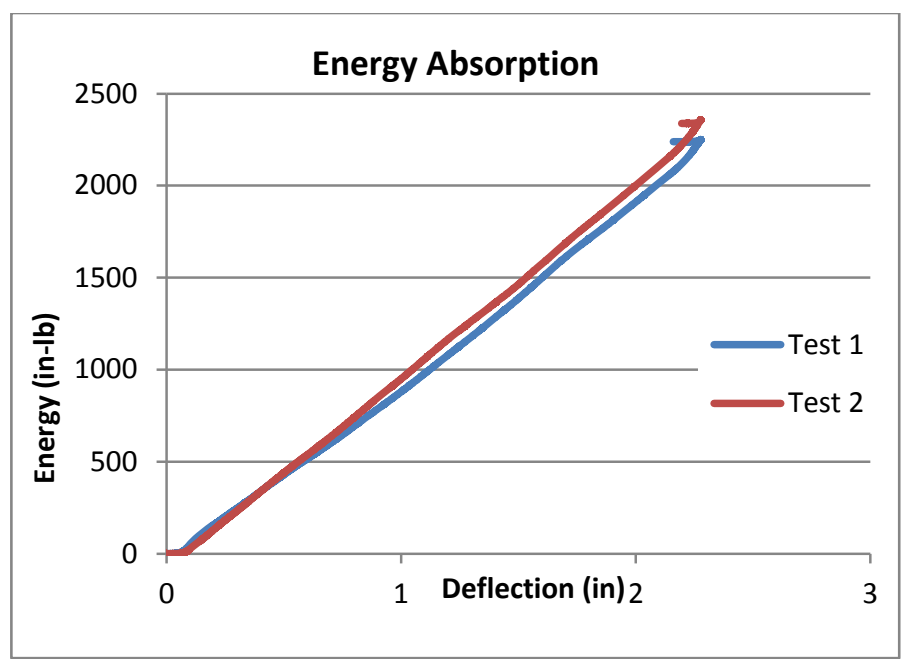

Figure 18. Honeycomb Energy Absorption test results

\section{CONCLUSIONS}

A crash environment was described for a cab engineer in which adequate survival space was preserved, but subjected the engineer to a severe deceleration pulse. An acceleration pulse more severe than the typical $8 \mathrm{~g}$ acceleration pulse used in rail occupant protection standards, but less severe than that for a typical automotive crash, was chosen to represent the collision environment. Several existing cab designs were reviewed and measured and a baseline cab design was developed.

A prototype system design was developed to protect the engineer in the baseline cab under the prescribed collision conditions. This system included a large, passenger style airbag with a standard inflator and a knee bolster that features off the shelf crushable honeycomb and a deformable bracket.

Four component tests were performed to validate engineering models. A static airbag test verified the inflation kinematics, timing and deployed airbag shape. A drop tower airbag test measured the dropped mass acceleration, allowed computer models to be verified, and provided the forcedisplacement characteristic for the airbags. Quasi-static tests of the knee bracket and the aluminum honeycomb measured the respective force-displacement characteristics.

All the tests were performed in accordance with the test requirements and all the test specimens performed as intended. All of the component computer models have been validated. The next step in this project is to combine the validated component models into a full occupant dynamic model. If the full occupant protection model predicts that the scenario is survivable for the $95^{\text {th }}$ percentile ATD, the next phase of the project may include a full scale test of the system with an ATD. Future research also includes examining the protection offered to a $5^{\text {th }}$ percentile ATD. This will be conducted using validated computer models.

\section{ACKNOWLEDGMENTS}

This work was sponsored by the Equipment Safety Research Program of the Federal Railroad Administration's

"This material is declared a work of the U.S. Government and is not subject to copyright protection in the United States. Approved for public release; distribution is unlimited." 
Office of Research Development. Kevin Kesler and Jeff Gordon are the program managers for this program.

The Volpe Center framed this work and has monitored the contract with Sharma.

Sharma \& Associates managed the design, testing and modeling effort, including the review of current cab designs and concept development.

Altair modeled, in RADIOSS, the full engineer protection system.

Key Safety Systems modeled, in MADYMO, the airbag tests and assisted with the airbag design.

\section{REFERENCES}

[1] Code of Federal Regulations, Title 49, Part 571, Section 208, Occupant Crash Protection, October 1, 2002.

[2] Priante, M. "Review of a Single Car Test of Multi-Level Passenger Equipment" American Society of Mechanical Engineers, Paper No. JRC2008-63053, April 2008.

[3] APTA SS-C\&S-016-99, Rev 2, Standard for Passenger Seats in Intercity and Commuter Rail Cars, October 3, 2010. The American Public Transportation Association, Washington, DC.

[4] Severson, K., Parent, D., "Train-to-Train Impact Test of Crash Energy Management Passenger Rail Equipment: Occupant Experiments," American Society of Mechanical Engineers, Paper No. IMECE2006-14420, November 2006.

[5] GM/RT 2100 Issue 4, Structural Requirements For Railway Vehicles, December 2010.

[6] Priante, M., Martinez, E., "Crash Energy Management Crush Zone Designs: Features, Functions, and Forms," Proceedings of the 2007 ASME/IEEE Joint Rail Conference \& Internal Combustion Engine Spring Technical Conference, JRCICE2007-40051, March 2007.

[7] Federal Railroad Administration. (1998). Human Factors Guidelines for Locomotive Cabs, DOT/FRA/ORD98/03, Multer, J., Rudich, R., Yearwood, K., May1998

[8] Zolock, J., Tyrell, D., "Locomotive Cab Occupant Protection," American Society of Mechanical Engineers, Paper No. IMECE2003-44121, November 2003.

[9] MADYMO, Version 7.0, TNO Automotive, Delft, The Netherlands.

[10] Radioss, Version 10, Altair Hyperworks, Troy Michigan, USA

"This material is declared a work of the U.S. Government and is not subject to copyright protection in the United States. Approved for public release; distribution is unlimited." 